\title{
Long-term effects of Nigella sativa L. oil on some physiological parameters in normal and streptozotocin-induced diabetic rats
}

\author{
Ayed Al-Logmani ${ }^{1}$, Talal Zari ${ }^{2^{*}}$ \\ ${ }^{1}$ Northern Border University, Arrar, Saudi Arabia; \\ ${ }^{2}$ King Abdulaziz University, Jeddah, Saudi Arabia; ${ }^{*}$ Corresponding Author: talzari@yahoo.com
}

Received 27 May 2011; revised 10 July 2011; accepted 19 July 2011.

\begin{abstract}
The long-term effects of Nigella sativa L. oil on some physiological parameters were investigated in normal and streptozotocin (STZ)-induced diabetic male Wistar rats. STZ-induced diabetic rats showed significant increases in the levels of blood glucose, triglycerides, cholesterol, low density lipoprotein (LDL-cholesterol), uric acid, urea, creatinine, alanine aminotransferase (ALT) and aspartate aminotransferase (AST) while high density lipoprotein (HDL-cholesterol) and total protein levels were significantly decreased compared to normal rats. Administration of black seed oil to diabetic rats resulted in a significant decrease in blood glucose, triglycerides, cholesterol, LDL-cholesterol ALT, AST and uric acid while HDL-cholesterol level was markedly increased compared to untreated diabetic rats after seven weeks of treatment. The results of this study indicate that the diet containing the oil of $\mathrm{N}$. sativa improves the examined physiological parameters in STZ- induced diabetic rats especially when it is used for a longer period.
\end{abstract}

Keywords: Streptozotocin; Diabetes; Black Seed Oil; Rats

\section{INTRODUCTION}

Diabetes mellitus is probably the fastest growing metabolic disorder in the world and it is a major source of morbidity in developed countries. Medicinal plants play an important role in the management of diabetes mellitus especially in developing countries where resources are meager. Many studies have confirmed the benefits of medicinal plants with hypoglycaemic effects in the management of diabetes mellitus. The effects of these plants may delay the development of diabetic complications and correct the metabolic abnormalities $[1,2]$. Moreover, during the past few years some of the new bioactive drugs isolated from hypoglycaemic plants showed antidiabetic activity with more efficacy than oral hypoglycaemic agents used in clinical therapy [3]. Presently, there is an increased demand to use natural products with antidiabetic activity due to the side effects associated with the use of insulin and oral hypoglycemic agents [4-6]. More than 400 plants with glucose lowering effect are known [7]. Also a number of plants have a hypolipidemic effect [8]. However, there is little information about plants with both hypoglycemic and hypolipidemic effects [9].

The pathogenesis of diabetes mellitus is managed by insulin and oral administration of hypoglycemic drugs such as sulfonylureas and biguanides [10]. Unfortunately, apart from having a number of side effects, none of the oral synthetic hypoglycemic agents have been successful in maintaining euglycaemia and controlling long-term microvascular and macrovascular complications [10-12]. Insulin therapy is used for management of diabetes mellitus but there are several drawbacks, which include insulin allergy, insulin antibodies, lipodystrophy, autoimmunity and other delayed complications like morphological changes in kidney and severe vascular complications [13-15]. Thus, new, relatively non-toxic, therapeutic agents are needed to treat hyperglycemia, which also would correct dyslipidemia to reduce the risk of cardiovascular complications of diabetes [16].

Nigella sativa L. (N. sativa) is a spice plant belonging to the family Ranunculaceae. It is cultivated in several countries in the Mediterranean region and Asia, known in vernacular as "sannouj, habbat el Baraka or habbah saouda" [17]. The seeds were used in the orient as condiments or flavourings and also in traditional medicine 
applications [18]. It has been shown that $N$. sativa has bronchodilatory $[19,20]$, anti bacterial [21], hypotensive [22], immunopotentiating [23], antioxidant [24], antitumoral [25] and antidiabetic properties [26-28]. The oil of $N$. sativa was potent analgesic and anti-inflammatory drug in rats [29,30] and had in vitro and in vivo cytotoxic and immunosuppressive properties [31]. The petroleum ether extract exerted lipid-lowering and insulin-sensitizing actions in rats [32].

Induction of diabetes in laboratory animals is a convenient and useful strategy in the understanding and treatment of the disease. An appropriate dose of streptozotocin was used to induce experimental diabetes. Streptozotocin selectively destroyed pancreatic $\beta$-cells, resulting in hypoinsulinemia [33]. Streptozocin-treated rats are often used as diabetic animals with insulin-deficiency resulting from damage of beta-cells caused by the drug. These rats are hyperglycemic and have reduced uptake of glucose in skeletal muscles [34-36]. It is generally considered that hyperglycemia is the major factor in the pathogenesis of diabetic complications [37]. In diabetes there is inability to store fat and protein along with breakdown of existing fat and protein stores. Streptozotocin induced diabetic rats showed significant increases in the levels of cholesterol, phospholipids, triglycerides, and free fatty acids [38,39]. These changes remain important in terms of explaining the accelerated atherosclerosis. In addition, there is a loss of body weight $[40,41]$. Impairment of kidney function is a prominent feature of diabetes. Elevated levels of urea and decreased concentrations of uric acid and creatinine were shown in diabetes $[42,43]$. Overtime diabetic nephropathy will develop, characterized by proteinuria, a loss of renal function, and a rapid progression to end stage renal failure [44].

Little information exists concerning the effects of $N$. sativa oil on physiological parameters in normal and STZ-induced diabetic rats. Therefore, the aim of this study is to find if the administration of the oil of $N$. $s a-$ tiva could have beneficial effects on some physiological parameters in normal and STZ-induced diabetic rats after seven weeks. The physiological parameters include blood glucose, triglycerides, cholesterol, high density lipoprotein HDL-cholesterol, low density lipoprotein LDL-cholesterol, total protein, creatinine, urea, uric acid, alanine aminotransferase (ALT) and aspartate aminotransferase (AST).

\section{MATERIALS AND METHODS}

\subsection{Materials}

Streptozotocin (STZ) was purchased from Sigma Chemical Co. (St. Louis, MO, USA). All other chemi- cals were purchased from Al-Saggaf Est. (Jeddah, Saudi Arabia). The oil of N. sativa was obtained from Dreams Essential Oils Est. (Jeddah, Saudi Arabia). N. sativa oil was extracted by steam. The major compounds of this oil were thymoquinone $(29.7 \%)$, p-cymene $(23 \%)$, carvacrol (11.5\%), $\alpha$-pinene (8.6\%), 4-terpineol (3.7\%), longifoline $(2.8 \%)$, carvone $(1.8 \%)$ and t-anethole $(0.8 \%)$.

\subsection{Experimental Animals}

Male Wistar rats weighing (180 - 230 g) were obtained from the Animal Experimental Unit of King Fahd Medical Research Center, King Abdul Aziz University, Jeddah, Saudi Arabia. The rats were housed in well- aerated cages in an animal room and maintained in a temperature-controlled room $\left(24^{\circ} \mathrm{C} \pm 1^{\circ} \mathrm{C}\right)$ with a $12 \mathrm{~h}$ light $/ 12 \mathrm{~h}$ dark cycle, $55 \% \pm 10 \%$ humidity. They were fed with normal commercial chow and water ad libitum. Throughout the experiments, animals were processed according to the suggested international ethical guidelines for the care of laboratory animals and all experimental procedures were approved by the Animal Care and Use Committee of King Abdul Aziz University.

\subsection{Induction of Diabetes}

The experimental animals were fasted for $12 \mathrm{~h}$ and then diabetes was induced by a single intraperitonial injection of streptozotocin (Sigma Chemical Co., St. Louis, MO, USA), dissolved in a freshly prepared physiological saline solution $(0.9 \% \mathrm{NaCl})$ at a dose of $65 \mathrm{mg} / \mathrm{kg}$ body weight. While normal rats received only the saline solution $(0.9 \% \mathrm{NaCl})$ in the same volume and through the same route. After injection, all animals were returned to their cages and given free access to food and water. After 3 days, the fasting blood glucose levels were measured from tail blood samples by using an OneTouch Ultra ${ }^{\circledR}$ glucometer (Lifescan; Johnson \& Johnson, Milpitas, CA, USA). Animals with blood glucose levels more than 277 $\mathrm{mg} / \mathrm{dL}$ were considered diabetic and used for the experiment.

\subsection{Experimental Design}

A total of 40 rats were used in the experiment. The rats were divided into 4 groups of 10 animals each as follows: Group 1: Normal control (non-diabetic normal rats) received normal commercial chow and water ad libitum. Group 2: STZ-Control (diabetic control rats) received the same diet given in group 1. Group 3: STZ + $N$. sativa oil received diet containing $5 \% N$. sativa oil. Group 4: Normal control $+N$. sativa oil received diet containing $5 \% N$. sativa oil. All of the experimental groups received the treatments for a period of 7 weeks. 


\subsection{Blood Collection}

After 7 weeks, the rats were fasted for $8 \mathrm{~h}$ before blood sampling, water was not restricted. Blood samples were collected from the orbital venous plexus of the rat under mild ether anaesthesia by heparinized capillary tube and into non-heparinized tubes [45] indicated that brief exposure and little amount of anesthetic used do not influence the activity of hepatic cytochrome P450 $2 \mathrm{E} 1$ and $\mathrm{P} 450$ reductases in the rat. Clear serum samples were separated by centrifugation at $3000 \mathrm{rpm}$ for $20 \mathrm{~min}$ and then collected and stored at $-20^{\circ} \mathrm{C}$ for different biochemical analyses, prior immediate determination of glucose, triglycerides, cholesterol, high density lipoprotein HDL-cholesterol (HDL-C), low density lipoprotein LDL-cholesterol (LDL-C), total protein, creatinine, urea, uric acid, alanine aminotransferase (ALT) and aspartate aminotransferase (AST). All of these parameters were measured using an automatic analyzer (Architect c8000 Clinical Chemistry System, USA).

\subsection{Statistical Analysis}

Statistical analyses were performed using SPSS package for Windows version 13.0. Data are expressed as mean $\pm \mathrm{SE}$. One-way ANOVA and t-tests were used to analyze differences among groups. Differences between groups were considered statistically significant at $\mathrm{p}<$ 0.05 .

\section{RESULTS}

The mean values of blood glucose of both control and experimental groups are presented in Table 1. STZ-induced diabetic rats showed a highly significant $(\mathrm{p}<$ 0.001 ) increase in the levels of blood glucose, registering increases of $246.2 \%$ after 7 weeks compared to the controls. Administration of $N$. sativa oil to diabetic rats resulted in a significant $(\mathrm{p}<0.001)$ decrease in blood glucose levels of $64.9 \%$ after 7 weeks, compared to untreated diabetic rats. In comparison with control, administration of black seed oil in non-diabetic rats showed no significant differences in the level of blood glucose after 7 weeks.

The changes in the levels of serum lipids in control and experimental groups are illustrated in Table 1. There was a significant $(\mathrm{p}<0.001)$ decrease in the level of HDL-cholesterol $(24.2 \%)$ and significant $(\mathrm{p}<0.001)$ increases in the levels of cholesterol, LDL-cholesterol and triglycerides in STZ-induced diabetic rats, with percentages of $64.7 \%, 70.9 \%$ and $176.1 \%$ respectively, compared to the controls. However, treatment of STZinduced diabetic rats with $N$. sativa oil resulted in a significant $(\mathrm{p}<0.001)$ decrease in the levels of triglycerides, cholesterol and LDL-cholesterol compared to untreated diabetic rats. While HDL-cholesterol level was significantly $(\mathrm{p}<0.001)$ increased after 7 weeks. On other hand, normal rats fed on $N$. sativa oil showed no significant differences in the levels of blood triglycerides, cholesterol, HDL-cholesterol and LDL-cholesterol after 7 weeks compared to control.

The mean values of blood total protein, urea, uric acid and creatinine concentrations of both control and experimental groups are presented in Table 2 . STZ-induced diabetic rats showed a significant $(\mathrm{p}<0.05)$ decrease in blood total protein with percentage of $7 \%$ compared to the control. In contrast, STZ-induced diabetic rats showed a significant $(\mathrm{p}<0.001)$ increase in blood uric acid, urea and creatinine by $23.7 \%, 155.4 \%$ and $29.7 \%$ respectively, compared to the control. Administration of $N$. sativa oil to diabetic rats resulted in a significant $(p<0.01)$ decrease in the levels of uric acid by $30 \%$ while there were no significant differences in the levels of total protein, urea and creatinine after 7 weeks, compared to untreated diabetic rats. In comparison with control, administration of black seed oil in non-diabetic rats showed no significant differences in the level of blood total protein, urea, uric acid and creatinine after 7 weeks.

Table 2 shows the mean values of AST and ALT activities of both control and experimental groups after 7 weeks. In STZ-induced diabetic rats the activities of blood AST and ALT were significantly ( $p<0.001)$ increased by $38.9 \%$ and $136 \%$, respectively, compared to their normal levels. On the other hand, treatment of the STZ-induced diabetic rats with $N$. sativa oil caused reduction in the activity of these enzymes in blood by $36.1 \%$ for AST and by $55.9 \%$ for ALT, compared to the

Table 1. Effects of $N$. sativa oil supplementation on blood glucose, triglyceride, cholesterol, LDL-C and HDL-C in rats.

\begin{tabular}{|c|c|c|c|c|}
\hline \multirow{2}{*}{ Parameters } & \multicolumn{4}{|c|}{ Treatment } \\
\hline & Normal control & STZ & STZ + Black seed oil & Black seed oil \\
\hline Glucose (mg/dl) & $126.72 \pm 2.17 * * *$ & $438.70 \pm 4.48^{\# \# \#}$ & $153.84 \pm 1.85 * * *$ & $125.56 \pm 2.84 * * *$ \\
\hline Triglyceride(mg/dl) & $55.55 \pm 5.27 * * *$ & $153.40 \pm 6.52^{\# \# \# ~}$ & $89.69 \pm 1.39 * * *$ & $50.68 \pm 8.75 * * *$ \\
\hline Cholesterol (mg/dl) & $62.39 \pm 3.11 * * *$ & $102.77 \pm 2.14^{\# \# \#}$ & $78.53 \pm 2.62 * * *$ & $61.84 \pm 2.74 * * *$ \\
\hline HDL-C (mg/dl) & $20.37 \pm 0.46 * * *$ & $15.45 \pm 0.50^{\# \# \#}$ & $19.01 \pm 0.19 * * *$ & $18.96 \pm 0.47 * * *$ \\
\hline LDL-C (mg/dl) & $31.63 \pm 0.55 * * *$ & $54.06 \pm 1.37^{\# \# \#}$ & $40.87 \pm 2.42 * * *$ & $31.84 \pm 2.39 * * *$ \\
\hline
\end{tabular}

The number of animals was 5 for each treatment except for the control and STZ, in which it was 10;All values are expressed as means \pm SE; Significantly different from untreated STZ-induced diabetic rats $(* \mathrm{p}<0.05, * * \mathrm{p}<0.01$ and $* * * \mathrm{p}<0.001)$; Significantly different from control $\left({ }^{\#} \mathrm{p}<0.05\right.$, \#\# $<0.01$ and ${ }^{\# \# \#}$ $\mathrm{p}<0.001)$ 
Table 2. Effects of $N$. sativa oil supplementation on blood total protein, urea, uric acid, creatinine, AST and ALT in rats.

\begin{tabular}{|c|c|c|c|c|}
\hline \multirow{2}{*}{ Parameters } & \multicolumn{4}{|c|}{ Treatment } \\
\hline & Normal control & STZ & STZ + Black seed oil & Black seed oil \\
\hline Total protein $(\mathrm{g} / \mathrm{L})$ & $6.53 \pm 0.08^{* *}$ & $6.07 \pm 0.09^{\# \#}$ & $6.10 \pm 0.09$ & $6.32 \pm 0.08$ \\
\hline Creatinine (mg/dl) & $0.37 \pm 0.02 * *$ & $0.48 \pm 0.03^{\# \#}$ & $0.43 \pm 0.02$ & $0.29 \pm 0.06^{* * *}$ \\
\hline Uric acid (mg/dl) & $0.97 \pm 0.04 *$ & $1.20 \pm 0.07^{\#}$ & $0.84 \pm 0.11^{* *}$ & $1.01 \pm 0.0$ \\
\hline Urea (mg/dl) & $16.87 \pm 0.50 * * *$ & $43.08 \pm 4.28^{\# \#}$ & $33.11 \pm 4.44$ & $15.35 \pm 1.12^{* * *}$ \\
\hline $\operatorname{AST}(\mathrm{U} / \mathrm{L})$ & $96.50 \pm 2.90 * * *$ & $134.00 \pm 8.20^{\# \#}$ & $85.60 \pm 4.63 * * *$ & $89.60 \pm 2.38^{* * *}$ \\
\hline $\operatorname{ALT}(\mathrm{U} / \mathrm{L})$ & $46.10 \pm 2.06 * * *$ & $108.80 \pm 9.92^{\# \#}$ & $48.00 \pm 3.78 * * *$ & $43.40 \pm 2.27 * * *$ \\
\hline
\end{tabular}

The number of animals was 5 for each treatment except for the control and STZ, in which it was 10 ; All values are expressed as means \pm SE; Significantly different from untreated STZ-induced diabetic rats $(* \mathrm{p}<0.05, * * \mathrm{p}<0.01$ and $* * * \mathrm{p}<0.001)$; Significantly different from control $\left(^{\#} \mathrm{p}<0.05\right.$, ${ }^{\#} \mathrm{p}<0.01$ and \#\#\# $\mathrm{p}<0.001)$.

mean values of untreated diabetic group. In comparison with control, administration of black seed oil in non-diabetic rats showed no significant differences in activities of blood AST and ALT after 7 weeks.

\section{DISCUSSION}

Results of the present study showed that diabetic rats exhibited a significant increase in blood glucose level. This result is in consistent with other studies in rats $[1,46,47]$. Numerous studies demonstrated that a variety of plant extracts effectively lowered the glucose level in STZ-induced diabetes mellitus rats [48-50]. In the present study, the oil of $N$. sativa significantly reduces blood glucose levels in STZ-induced diabetic rats after 7 weeks of treatment, which also demonstrates that there is significantly higher rate of glucose disposal. In a previous study, the oil of $N$. sativa significantly reduces blood glucose levels in STZ-induced diabetic rats after 3 weeks of treatment [2]. Similar observations were also obtained by Al-Awadi et al. [26], who reported that plant mixture extract comprising of $N$. sativa, Myrrh, Gum olibanum, Gum asafetida and Aloe to have a blood glucose lowering effect. Also, the intraperitoneal administration of volatile oil of $N$. sativa to fasting normal and alloxondiabetic rabbits produced significant hypoglycemic effects [51]. Hyperglycemia increases the generation of free radicals by glucose auto-oxidation and the increment of free radicals may lead to liver cell damage. The increase in oxygen free radicals in diabetes could be primarily due to the increase in blood glucose levels and secondarily due to the effects of the diabetogenic agent streptozotocin [33]. Previous studies demonstrated that the essential oils of black seed and their active constituents have proven free radical scavenging and antioxidant activities [24,52,53]. Based on above mentioned reports, it is suggested that the possible mechanism of action by the oil of $N$. sativa could be related to antioxidants that aid to recover from impaired metabolism of glucose [2]. The diabetes caused by streptozotocin administration increases fat mobilization in skeletal muscle [54] inducing significant weight loss [55]. Lipids play a vital role in the pathogenesis of diabetes mellitus. The most common lipid abnormalities in diabetes are hypertriglyceridemia and hypercholesterolemia [56]. In our study, we have noticed significantly increased levels of serum total cholesterol, triglycerides and LDL-cholesterol but markedly decreased level of serum HDL-cholesterol in STZ-induced diabetic rats. These results are in agreement with those obtained by $[39,40,57,58]$. The abnormal high concentrations of serum lipids in diabetic animals are due mainly to an increase in the mobilization of free fatty acids from the peripheral fat depots, since insulin inhibits the hormone-sensitive lipase [59]. Excess fatty acids in the serum of diabetic rats are converted into phospholipids and cholesterol in the liver. These two substances along with excess triglycerides formed at the same time in the liver may be discharged into the blood in the form of lipoproteins [60].

The present study showed that $N$. sativa oil had favourably modified serum lipid profile in rats with significant decreases in total cholesterol, LDL-cholesterol, triglycerides and increased HDL. Moreover, the effects of $N$. sativa oil on the tested physiological parameters in streptozotocin-diabetic rats are more beneficial after 7 weeks than after 3 weeks [2]. In this study, the $\mathrm{STZ}+N$. sativa oil group showed significant decreases in the levels of glucose $(15.97 \%)$, triglyceride $(6.21 \%)$ and cholesterol $(7.1 \%)$ after 7 weeks when compared with those after 3 weeks [2]. Zaoui et al. [61] reported that serum cholesterol, triglycerides and glucose levels were significantly decreased in $N$. sativa oil ( $1 \mathrm{ml} / \mathrm{kg} /$ day) for 12 
weeks treated rats. The antilipidemic action of $N$. sativa oil may reside in their ability to stimulate insulin secretion and action. Fararh et al. [62] investigated the possible insulinotropic properties of $N$. sativa oil in streptozotocin plus nicotinamide-induced diabetes mellitus in hamsters. The results of their study indicate that there is a significant decrease in blood glucose level together with significant increase in serum insulin level after treatment with $N$. sativa oil for 4 weeks. In addition, there are big areas with positive immuno-reactivity for the presence of insulin in the pancreases from $N$. sativa oil-treated group compared to non-treated one using immunohistochemical staining. These data show that the hypoglycemic effect of $N$. sativa oil in streptozotocin plus nicotinamide diabetic hamsters resulted, at least partly, from a stimulatory effect on $\beta$ cell function with consequent increase in serum insulin level. Therefore, these results indicate that $N$. sativa oil has insulinotropic properties in type 2-like model.

Cardiovascular disease (CVD) is directly related to plasma concentration of low density lipoprotein cholesterol (LDL-C) and inversely related to high density lipoprotein cholesterol (HDL-C) [63]. Increased levels of LDL are linked with cardiovascular disease; more specifically, it has been reported that oxidation of LDL particles is likely a key step in the development of atherosclerotic plaques [64]. Recent evidence suggests that lipid-lowering therapy reduces cardiovascular morbidity and mortality and causes regression of coronary atherosclerosis [65]. Zahida et al. [66] reported that $N$. sativa has ability to reduce lipid profile which is a major risk factor for coronary artery disease in cardiac patients. The exact mechanism of action of $N$. sativa is not known, however, it has been proved that volatile oil of $N$. sativa has two main constituents i.e. nigellone and thymoquinone which play a key role in heart disease prevention [67-69]. According to Feldman [70] antioxidants (e.g., vitamins $\mathrm{E}$ and $\mathrm{C}$ ) may lessen the risk CVD by decreasing oxidized LDL, which is more atherogenic. Thymoquinone (TQ) and ter-butylhydroquinone (TBHQ) of $N$. sativa have strong antioxidant potentials through scavenging ability of different free radicals [71].

The data revealed significant elevations in blood urea, uric acid and creatinine concentrations in STZ-induced diabetic rats. A similar effect was recorded previously [42]. A decrease in body weight of diabetic rats is possible due to catabolism of fats and protein, even though the food intake is more in diabetic rats than control. Due to insulin deficiency protein content is decreased in muscular tissue by proteolysis [72]. The highly signifycant increase in serum urea concentrations of diabetic rats may be due to depletion of serum protein, increase in the rate of circulating amino acids and deamination takes place that consequently leads to the formation of large amount of ammonia which is eventually converted to urea. The breakdown of amino acids during gluconeogenesis in the liver results in increased production of urea, fostering negative nitrogen balance [73]. In contrast, serum total protein was decreased in diabetic animals. The decrease in blood total protein observed in diabetic rats is coinciding with the findings of [74] and [75]. This decline may be due to the inhibited oxidative phosphorylation processes which lead to decrease of protein synthesis, increase in the catabolic processes and reduction of protein absorption [76,77]. Previous changes in serum urea, uric acid and creatinine concentrations strongly suggested impairment of kidney function in diabetes. The treatment with $N$. sativa oil lead to significant decreases in the levels of uric acid in STZ-induced diabetic rats compared to untreated STZ-induced diabetic rats after 7 weeks. The main effect of the N. sativa oil is presumably due to its ability to increase insulin secretion [2].

In STZ-induced diabetic rats the activities of blood AST and ALT were significantly increased compared to their normal levels. These results indicated that diabetes may be induced due to liver dysfunction [78] also found that liver was necrotized in STZ-induced diabetic rats. Therefore, increase in the activities of AST and ALT in blood may be mainly due to the leakage of these enzymes from the liver cytosol into the blood stream [79], which gives an indication on the hepatotoxic effect of STZ. On the other hand, treatment of the diabetic rats with $N$. sativa oil caused reduction in the activity of these enzymes in blood compared to the mean values of diabetic group and consequently may alleviate liver damage caused by STZ-induced diabetes. These results are in agreement with those obtained by [9] who reported that oral administration of cinnamaldehyde for 45 days significantly restores the enzyme levels to near normal in diabetic rats. A possible explanation for the differential effects of $N$. sativa oil on the activities of AST and ALT in blood is that these treatments may inhibit the liver damage induced by streptozotocin [2].

\section{CONCLUSIONS}

The results of this study indicate that black seed oil possesses hypoglycemic, hypolipidemic and antioxidant effects in STZ-induced diabetic rats and suggest that this oil may be an excellent adjuvant support in the therapy of diabetes and its complications especially when it is used for a longer period.

\section{REFERENCES}

[1] Al-Attar, A. and Zari, T. (2007) Modulatory effects of ginger and clove oils on physiological responses in streptozotocin-induced diabetic rats. International Journal 
of Pharmacology, 3, 34-40.

[2] Al-Logmani, A. and Zari, T. (2009) Effects of Nigella sativa L. and Cinnamomum zeylanicum Blume oils on some physiological parameters in streptozotocin-induced diabetic rats. Boletín Latinoamericano y del Caribe de Plantas Medicinales y Aromáticas, 8, 86-96.

[3] Bnouham, M., Ziyyat, A., Mekhfi, H., Tahri, A. and Legssyer, A. (2006) Medicinal plants with potential antidiabetic activity - A review of ten years of herbal medicine research (1990-2000). International Journal of Diabetes and Metabolism, 14, 1-25.

[4] Holman, R. and Turner, R. (1991) Oral agents and insulin in the treatment of NIDDM. In: Pickup, J. and Williams, G., Ed., Textbook of Diabetes, Blackwell, Oxford, 467-469.

[5] Kameswara, Rao, B., Giri, R., Kesavalu, M. and Appa Rao, Ch. (1997) Herbal medicine in the management of diabetes mellitus. Manphar Vaidhya Patrika, 1, 33-35.

[6] Kim, S., Hyun, S. and Choung, S. (2006) Anti-diabetic effect of cinnamon extract on blood glucose in $\mathrm{db} / \mathrm{db}$ mice. Journal of Ethnopharmacology, 104, 119-123. doi:10.1016/i.jep.2005.08.059

[7] Ernst, E. (1997) Plants with hypoglycemic activity in humans. Phytomedicine, 4, 73-78.

[8] Sharma, S., Nasir, A., Prabhu, K., Murthy, P. and Dev, G. (2003) Hypoglycaemic and hypolipidemic effect of ethanolic extract of seeds of Eugenia jambolana in alloxan-induced diabetic rabbits. Journal of Ethnopharmacology, 85, 201-206. doi:10.1016/S0378-8741(02)00366-5

[9] Subash B.P., Prabuseenivasan, S. and Ignacimuthu, S. (2006) Cinnamaldehyde-A potential antidiabetic agent. Phytomedicine, 14,15-22. doi:10.1016/j.phymed.2006.11.005

[10] Larner, J. (1985) Insulin and oral hypoglycaemic drugs, glucagon. In: Gilman, A. Goodman, L. Rall, T. and Murad, F., Eds., The Pharmacological Basis of Therapeutics, Macmillan, New York, 149-151.

[11] Momin, A. (1987) Role of indigenous medicine in primary health care. Proceedings of First International Seminar on Unani Medicine, New Delhi, India, 54.

[12] Stenman, S., Groop, P., Laakkonen, K., Wahlin-Boll, E. and Melander, A. (1990) Relationship between sulfonylurea dose and metabolic effect. Diabetes, 39, 108.

[13] Defronzo, R., Hendeler, R. and Simonson, D. (1982) Insulin resistance is a prominent feature of insulin dependent diabetes. Diabetes, 31, 795-801.

[14] Jarvinen, Y. and Koivisto, V. (1984) Insulin sensitivity in newly diagnosed type-I diabetes following ketoacidosis after a three month insulin therapy. Journal of Clinical Endocrinology and Metabolism, 59, 371-378. doi:10.1210/jcem-59-3-371

[15] Jarvinen, Y. and Koivisto, V. (1986) Natural course of insulin resistance in type-I diabetes. The New England journal of medicine, 315, 224-230. doi:10.1056/NEJM198607243150404

[16] El-Hilaly, J., Tahraoui, A., Israili, Z. and Lyoussi, B. (2006) Hypolipidemic effects of acute and subchronic administration of an aqueous extract of Ajuga iva L. whole plant in normal and diabetic rats. Journal of Ethnopharmacology, 105, 441-448. doi:10.1016/j.jep.2005.11.023

[17] Rchid, H., Chevassus, H., Nmila, R., Guiral, C., Petit, P.,
Chokaïri, M. and Sauvaire, Y. (2004) Nigella sativa extracts enhance glucose-induced insulin release from rat-isolated Langerhans islets. Fundamental \& Clinical Pharmacology, 18, 525-529. doi:10.1111/j.1472-8206.2004.00275.x

[18] Ballero, M. and Fresu, I. (1993) Le plante di uso officinale nella Barbagia di Scui (Sardegna Centrale). Fitoterapia, 64, 141-150.

[19] El-Dakhakhny, M. (1965) Egyptian Nigella sativa. Arzneimittel-Forsch, 15, 1227-1229.

[20] Mahfouz, M. and El-Dakhakhny, M. (1966) The isolation of a crystalline active principle from Nigella sativa seeds. Journal of Pharmaceutical Sciences, 1, 9-19.

[21] Toppozada, H., Mazloum, H. and El-Dakhakhny, M. (1965) The antibacterial properties of Nigella sativa seeds: Active principle with some clinical application. Journal of the Egyptian Medical Association, 48, 187-202.

[22] Mahfouz, M., El-Dakhakhny, M., Gemei, A. and Moussa, H. (1962) Choleretic action of Nigella sativa seed oil. Egyptian Pharmacology Bulletin, 44, 225-229.

[23] El-Kadi, A. and Kandil, O. (1987) The black seed (Nigella sativa) and immunity: Its effect on human $\mathrm{T}$ cell subset. Federation Proceedings, 46, 12-22.

[24] Burits, M. and Bucar, F. (2000) Antioxidant activity of Nigella sativa essential oil. Phytotherapy Research, 14, 323-328.

doi:10.1002/1099-1573(200008)14:5<323::AID-PTR621 $>3.0 . \mathrm{CO} ; 2-\mathrm{Q}$

[25] Worthen, D., Ghosheh, O. and Crooks, P. (1998) The in vitro anti-tumor activity of some crude and purified components of Black seed. Nigella sativa L. Anticancer Research, 18, 1527-1532.

[26] Al-Awadi, F., Khattar, M. and Gumaa, K. (1985) On the mechanism of the hypoglycemic effect of a plant extract. Diabetologia, 28, 432-434. doi:10.1007/BF00280886

[27] Bamosa, A., Ali, B. and Sowayan, S. (1997) Effect of oral ingestion of Nigella sativa seeds on some blood parameters. Saudi Pharmaceutical Journal, 5, 126-129.

[28] Meral, I., Yener, Z., Kahraman, T. and Mert, N. (2001) Effect of Nigella sativa on glucose concentration, lipid peroxidation, anti-oxidant defence system and liver damaga in experimentally-induced diabetic rabbits. Journal of Veterinary Medicine, 48, 593-599. doi:10.1046/j.1439-0442.2001.00393.x

[29] Houghton, P., Zarka, R., Las Heras, B. and Hoult, J. (1995) Fixed oil of Nigella sativa and derived thymoquinone inhibit eicosanoid generation in leukocytes and membrane lipid peroxidation. Planta Medica, 61, 33-36. doi:10.1055/s-2006-957994

[30] Hajhashemi, V., Ghannadi, A. and Jafarabadi, H. (2004) Black cumin seed essential oil, as a potent analgesic and antiinflammatory drug. Phytotherapy Research, 18, 195199. doi: $10.1002 /$ ptr. 1390

[31] Islam, S., Begun, P., Ahsan, T., Huque, S. and Ahsan, M. (2004) Immunosuppressive and cytotocic properties of Nigella sativa. Phytotherapy Research, 8, 395-398. doi:10.1002/ptr.1449

[32] Mai Le, P., Benhaddou-Andaloussi, A., Elimadi, A., Settaf, A., Cherrah, Y. and Haddad, P. (2004) The petroleum ether extract of Nigella sativa exerts lipid-lowering and insulin-sensitizing actions in the rat. Journal of Ethnopharmacology, 94, 251-259. 
doi:10.1016/i.jep.2004.04.030

[33] Szkudelski, T. (2001) The mechanism of alloxan and streptozotocin action in B cells of the rat pancreas. Physiological Research, 50, 537-46.

[34] Wallberg-Harrison, H. and Holoszy, J. (1985) Activation of glucose transport in diabetic muscle: Response to contraction and insulin. American Journal of Physiology, 249, 233-237.

[35] Goodyear, L., Hirshman, M., Knutson, S., Horton, E. and Horton, E. (1988) Effect of exercise training on glucose homeostasis in normal and insulin-deficient diabetic rats. Journal of Applied Physiology, 65, 844-851.

[36] Markun, J., Napoli, R., Hirshman, M., Davalli, A., Cheatham, B. and Goodyear, L. (1999) Effect of streptozocin-induced diabetes and ilst cell transplantation on insulin signaling in rat skeletal muscle. Endocrinology, 140, 106-111. doi:10.1210/en.140.1.106

[37] Odetti, P., Travers, O., Cosso, L., Noberasco, G., Pronzato, M. and Marinariu, M. (1996) Good glycemic control reduces oxidation and glycation end- products in collagen of diabetic rats. Diabetologia, 39, 1440-1447. doi:10.1007/s001250050596

[38] El-Agouza, I., Rawy, A., Saad, A., Lashin, A. and El-Sisi, S. (2000) Effect of sulfur containing amino acids and insulin injection on streptozotocin diabetic rats. Journal of Drug Research of Egypt, 23, 213-224.

[39] Ravi, K., Rajasekaran, S. and Subramanian, S. (2005) Antihyperlipidemic effect of Eugenia jambolana seed kernel on streptozotocin-induced diabetes in rats. Food and Chemical Toxicology, 43, 1433-1439. doi:10.1016/j.fct.2005.04.004

[40] Bolkent, S., Yanardag, R., Karabulut-Bulen, O. and Ozsoy-Sacan, O. (2004) The morphological and biochemical effects of glibornuride on rat liver in experimental diabetes. Human and Experimental Toxicology, 23, 257-264. doi:10.1191/0960327104ht444oa

[41] Zari, T. and Al-Attar, A. (2007) Effects of ginger and clove oils on some physiological parameters in streptozotocin-diabetic and non-diabetic rats. Journal of Medical Sciences, 7, 267-275. doi:10.3923/jms.2007.267.275

[42] Gawronska-Szklarz, B., Musial, D., Pawlik, A. and Paprota, B. (2003) Effect of experimental diabetes on pharmacokinetic parameters of lidocaine and MEGX in rats. Polish Journal of Pharmacology, 55, 619- 624.

[43] Yassin, M., Ashour, A. and Elyazji, N. (2004) Alterations in body weight, protein profile, non-protein nitrogen constituents and kidney structure in diabetic rats under glibenclamide treatment. Journal of the Islamic University of Gaza, 12, 65-82.

[44] Tesch, G. and Nikolic-Paterson, D. (2006) Recent Insights into Experimental Mouse Models of Diabetic Nephropathy. Nephron Experimental Nephrology, 104, 57-62. doi:10.1159/000093998

[45] Plate, A., Crankshaw, D. and Gallaher, D. (2005) The effect of anesthesia by diethyl ether or isoflurane on activity of cytochrome P450 2E1 and P450 reductases in rat liver. Anaesthesia and Analgesia, 101, 1063-1064. doi:10.1213/01.ane.0000166791.30963.ef

[46] Augusti, K. and Sheela, C. (1996) Antiperoxide effect of S-allyl cysteine sulfoxide, a insulin secretagogue, in diabetic rats. Experientia, 52, 115-120.

doi:10.1007/BF01923354
[47] Campos, K., Diniz, Y., Cataneo, A., Faine, L., Alves, J. and Novelli, E. (2003) Hypoglycaemic and antioxidant effects of onion, Allium cepa: Dietary onion addition, antioxidant activity and hypoglycaemic effects on diabetic rats. International Journal of Food Sciences and Nutrition, 54, 241-246. doi:10.1080/09637480120092062

[48] Ravi, K., Ramachandra, B. and Subramanian, S. (2004) Protective effect of Eugenia jambolana seed kernel on tissue antioxidants in streptozotocin induced diabetic rats. Biological and Pharmaceutical Bulletin, 27, 1212-1217. doi:10.1248/bpb.27.1212

[49] Rajasekaran, S., Sivagnanam, K. and Subramanian, S. (2005) Antioxidant effect of Aloe vera gel extract in streptozotocin-induced diabetes in rats. Pharmacological reports, 57, 90-96.

[50] Sekar, D., Sivagnanam, K. and Subramanian, S. (2005) Antidiabetic activity of Momordica charantia seeds on streptozotocin induced diabetic rats. Pharmazie, 60, 383-387.

[51] Al-Hader, A., Aqel, M. and Hasan, Z. (1993) Hypo-glycaemic effects of the volatile oil of Nigella sativa seeds. International Journal of Pharmacology, 31, 96-100. doi:10.3109/13880209309082925

[52] Tomaino, A., Cimino, F., Zimbalatti, V., Venuti, V., Sulfaro, V., De Pasquale, A. and Saija, A. (2005) Influence of heating on antioxidant activity and the chemical composition of some spice essential oils. Food Chemistry, 89, 549-554. doi:10.1016/j.foodchem.2004.03.011

[53] Jayaprakasha, G., Negi, P., Jena, B., Jagan, M. and Rao, L. (2007) Antioxidant and antimutagenic activities of Cinnamomum zeylanicum fruit extracts. Journal of Food Composition and Analysis, 20, 330-336. doi:10.1016/j.jfca.2006.07.006

[54] Stearns, S., Tepperman, H. and Tepperman, J. (1979) Studies on the utilization and mobilization of lipid in skeletal muscles from streptozotocin-diabetic and control rats. Journal of Lipid Research, 20, 654-662.

[55] Besse, S., Assayag, P., Delcayre, C., Carré, F., Cheav, S.L., Lecarpentier, Y. and Swynghedauw, B. (1993) Normal and hypertrophied senescent rat heart: Mechanical and molecular characteristics. American Journal of Physiology, 265, 183-190.

[56] Al-Shamaony, L., Al-khazrajoi, S. and Twaij, H. (1994) Hypoglycaemic effect of Artemisia herba alba. II. Effect of a valuable extract on some blood parameters in diabetic animals. Journal of Ethnopharmacology, 43, 167171. doi:10.1016/0378-8741(94)90038-8

[57] Singh, N., Kamath, V. and Rajini, P. (2005) Protective effect of potato peel powder in ameliorating oxidative stress in streptozotocin diabetic rats. Plant Foods for Human Nutrition, 60, 49-54. doi:10.1007/s11130-005-5099-y

[58] Rajasekaran, S., Ravi, K., Savgananam, K. and Subramanian, S. (2006) Beneficial effects of aloe vera leaf gel extract on lipid profile status in rats with streptozotocin diabetes. Clinical and Experimental Pharmacology and Physiology, 33, 232-237. doi:10.1111/j.1440-1681.2006.04351.x

[59] Pushparaj, P., Tan, C. and Tan, B. (2000) Effects of Averrhoe bilimli leaf extract on blood glucose and lipids in streptozotocin diabetic rats. Journal of Ethnopharma- 
cology, 72, 69-76. doi:10.1016/S0378-8741(00)00200-2

[60] Bopanna, K., Kannan, J., Sushma, G., Balaram, R. and Rathod, S. (1997) Antidiabetic and antihyperlipaemic effects of neem seed kernel powder on alloxan diabetic rabbits. Indian Journal of Pharmacology, 29, 162-167.

[61] Zaoui, A., Cherrah, Y., Alaoui, K., Mahassine, N., Amarouch, H. and Hassar, M. (2002) Effects of Nigella sativa fixed oil on blood homeostasis in rat. Journal of Ethnopharmacology, 79, 23-26. doi:10.1016/S0378-8741(01)00342-7

[62] Fararh, K., Atoji, Y., Shimizu, Y. and Takewaki, T. (2002) Insulinotropic properties of Nigella sativa oil in Streptozotocin plus Nicotinamide diabetic hamster. Research in Veterinary Science, 73, 279-282. doi:10.1016/S0034-5288(02)00108-X

[63] Chobanian, V.A., Dolecek, A.T. and Dustan, P.H. (1991) National education programme working group. Report on the management of patients with hypertension and high blood cholesterol. Annals of Internal Medicine, 114, 3.

[64] Luc, G. and Fruchart, J.C. (1991) Oxidation of lipoproteins and atherosclerosis. American Journal of Clinical Nutrition, 53, 206-209.

[65] Ridker, P.M., Danielson, E. and Fonseca, F.A. (2008) Rosuvastatin to prevent vascular events in men and women with elevated C-reactive protein. The New England Journal of Medicine, 359, 2195-207. doi:10.1056/NEJMoa0807646

[66] Zahida, T., Zeshan, S., Nisar, A. and Mushtaq, H.L. (2011) The Effects of Nigella sativa (Kalonji) on Lipid Profile in Patients with Stable Coronary Artery Disease in Multan, Pakistan. Pakistan Journal of Nutrition, 10, 162-167. doi:10.3923/pjn.2011.162.167

[67] Gad, A.M., El-Dakhakhny, M. and Hassan, M.M. (1963) Studies on the chemical composition of Egyptian Nigella sativa L. oil. Planta Medica, 11, 134-138. doi:10.1111/j.1365-2621.1978.tb15297.x

[68] Babayan, V.K., Koottungal, D. and Halaby, G.A. (1978) Proximate analysis, fatty acid and amino acid composition of Nigella sativa L. seeds. Journal of Food Science, 43, 1314-1315. doi:10.1111/j.1365-2621.1978.tb15297.x
[69] Abdel-Aal, E.S. and Attia, R.S. (1993) Characterization of black cumin (Nigella sativa) seeds. Alexandria Science Exchange, 14, 483-496.

[70] Feldman, E.B. (2001) Cardiovascular disease prevention by diet. In: Berdanier, C.D., Ed., CRC Handbook of $\mathrm{Nu}$ trition and Foods, CRC Press, Boca Raton.

[71] Badary, O.A., Taha, R.A., Gamalel-Din, A.M. and Abdel-Wahab, M.H. (2003) Thymoquinone is a potent superoxide anion scavenger. Drug. Chemical Toxicology, 26, 87-98. doi:10.1081/DCT-120020404

[72] Vats, V., Yadav, S. and Grover, J. (2004) Ethanolic extract of Ocimum sanctum leaves partially attenuates streptozotocin-induced alterations in glycogen content and carbohydrate metabolism in rats. Journal of Ethnopharmacology, 90, 155-160. doi:10.1016/j.jep.2003.09.034

[73] Ganong, W.F. (2003) Review of medical physiology, 21st Ed., Lange Medical Books, McGraw-Hill, New York.

[74] Peavy, D., Taylor, J. and Jefferson, L. (1985) Time course of changes in albumin synthesis and mRNA in diabetic and insulin-treated diabetic rats. American Journal of Physiology, 248, 656-663.

[75] Wanke, L. and Wong, N. (1991) Diabetes mellitus decreases the activity of the albumin promotor in vitro. The Journal of Biological Chemistry, 266, 6068-6072.

[76] Tragl, K. and Reaven, G. (1972) Effect of insulin deficiency on hepatic ribosomal aggregation. Diabetes, 21, 84-88.

[77] Jefferson, L., Liao, W., Peavy, D., Miller, T., Appel, M. and Taylor, J. (1983) Diabetes-induced alterations in liver protein synthesis: Changes in the relative abundance of mRNA for albumin and other plasma proteins. The Journal of Biological Chemistry, 258, 1369-1375.

[78] Ohaeri, O. (2001) Effect of garlic oil on the levels of various enzyme in the serum and tissue of streptozotocin diabetic rats. Bioscience Reports, 21, 19-24. doi:10.1023/A:1010425932561

[79] Navarro, C., Montilla, P., Martin, A., Jimenez, J. and Utrilla, P. (1993) Free radicals scavenger and antihepatotoxic activity of Rosmarinus. Plant Medicine, 59, 312314. doi:10.1055/s-2006-959688 